\title{
Pattern of use of positron emission tomography/computed tomography (PET/ CT) scan in non-colorectal gastrointestinal cancers at KFSHRC, Riyadh, Saudi Arabia
}

\author{
Ali Husain Aljubran ${ }^{1}$, Ahmed Badran ${ }^{1,2^{*}}$ (D), Omar Alshaer ${ }^{3}$, Hashem Alhashem ${ }^{1}$, Aymen Omar ${ }^{1,4}$ and \\ Abdelmoniem Eldali ${ }^{5}$
}

\begin{abstract}
Background: Positron emission tomography/computed tomography (PET/CT) scan is useful if clinically indicated. It is not for conventional routine use due to its high cost. Moreover, it can be confusing if ordered in non-indicated conditions. We evaluate if the pattern of PET/CT ordered in gastrointestinal cancers (non-colorectal origin) has followed evidence-based guidelines and whether it helped in the improvement of patient's outcome. This study included non-colorectal gastrointestinal cancer patients from 2007 to 2008 who had one or more PET/CT scans done during their management. In each case, data collected revealed whether PET/CT affected the management or the stage or not. Patients were identified through the hospital tumor registry software CNExT (C/NET Solutions, Berkeley, CA). Tabulation and statistical data analysis were done using JMP-SAS statistical software application (version 9.4: SAS Institute, Cary, NC, USA). The scan report quality and use indications were outlined.

Results: Seventy-seven patients were identified, with 107 PET/CT scans done. Their median age is 59 (21-86) years. Males were 45 (58.5\%). Tumor origin was $46.8 \%$ esophageal and gastroesophageal junction cancer, $15.6 \%$ gastric cancer, $11.7 \%$ pancreatic cancer, $11.7 \%$ hepatobiliary tumors, $10.4 \%$ neuroendocrine tumors, $2.6 \%$ gastrointestinal stromal tumors, and $1.3 \%$ small bowel cancer. Indications of the PET/CT were as follows: staging in 59.8\%, follow-up after finishing treatment in $14.9 \%$, restaging at relapse in $8.4 \%$, assessing response after/during treatment in $3.7 \%$, follow-up of previous PET/CT in 12.1\%, and others in 0.9\%. PET/CT changed the stage in 19.6\% and affected the management plan in $11.2 \%$ only. Fifty-two scans needed pathological pursuit as decided by investigators; of them, PET/CT for the lesions that could have changed the stage reported indeterminate/equivocal results in 32 (29.9\%) of all scans. The pathological pursuit for the equivocal lesions on PET/CT scans was done in only 12 of 52 (23.1\%) scans.

Conclusions: Local guidelines for ordering PET/CT scan are suggested because overuse was documented, and an evidence-based approach should be respected before its use.
\end{abstract}

Keywords: PET-CT, Gastrointestinal malignancy, Guidelines

\footnotetext{
* Correspondence: doctorbadran@med.asu.edu.eg; asobh@kfshrc.edu.sa

${ }^{1}$ Medical Oncology, Oncology Centre, King Faisal Specialist Hospital and

Research Center, MBC 64, PO Box 3354, Riyadh 11211, Saudi Arabia

${ }^{2}$ Department of Clinical Oncology, Faculty of Medicine, Ain Shams University,

Cairo, Egypt

Full list of author information is available at the end of the article
} 


\section{Background}

Gastrointestinal (GI) cancers are a heterogeneous group of tumors, with different biological and clinical behaviors, and no single imaging modality can provide all the necessary information for any given GI tumor [1]. Therefore, wellchosen combinations of available imaging modalities are required for optimal evaluation of GI cancer patients; it depends on indications, strength, and limitations of each modality [2].

Computed tomography (CT) scanning and magnetic resonance (MR) imaging provide an important and necessary anatomical evaluation of the tumor, and on the other hand, positron emission tomography (PET) provides a functional evaluation that is, in many case scenarios, not less important.

In the early 1970s, PET was developed, about the same time as MRI and after CT [3], and was introduced into clinical use in the 1990s. It works by using natural molecules (e.g., glucose or amino acid) after labeling them with positron emitting radioisotopes. FDG (fluorodeoxyglucose) is a glucose analog, and it is the most widely used isotope, characterized by having a relatively long half-life of $110 \mathrm{~min}$ [4].

Despite the important role and the amount of information that can be provided by PET scanning, it has many pitfalls that can sometimes confuse the treatment plan and negatively affect the outcome. The most important disadvantage is the relatively high levels of both false-negative and falsepositive results. Radiologists' reports of PET scans are sometimes uncertain and use equivocal expressions like indeterminate or suspicious. With false or equivocal results, the PET scan can be not only confusing but also misleading. It can deem some patients' incurable and make them avoid curative procedures or, on the other hand, can make some patients have unnecessary interventions.

The high cost is another important disadvantage. Production of the short-lived radionuclides is very costly. Maintenance is also costly, and few universities and medical institutes can maintain such systems [4].

As a result, it has become imperative to set guidelines for ordering PET scan. NCCN (National Comprehensive Cancer Network) set evidence-based recommendation for recommending PET/CT scan in the staging, followup, restaging at relapse, and assessing response to therapy in different GI cancers. NCCN guidelines stated recommendations of variable levels of strength in mainly two GI cancers, esophageal (including gastroesophageal) cancer and colorectal cancer, in the following case scenarios: [5]

- Esophageal cancer:

1. Staging

2. Response assessment after initial therapy
- Colorectal cancer: restaging after relapse in the following conditions:

1. In case of resectable liver or lung metastasis: to exclude extrahepatic or extrapulmonary disease respectively

2. In case of post-operative presacral density: to distinguish postoperative changes from residual or recurrent cancer

3. In case of persistently elevated CEA with negative CT scan: to search for occult disease especially peritoneal or ovarian metastases

PET scan has been available at our institute, since the 1990s. In October 2005, the integrated PET/ CT scan was introduced to the routine practice. Since then, a significant increase in its use in different clinical case scenarios was noticed. At the time of conducting this study, the average monthly performance of the exam is 450 .

There has been a strong notion among many physicians at our institute that PET/CT scan is overused and that there is weak adherence to the guidelines which makes PET/CT scan ordered almost routinely in many cases in the absence of appropriate indications.

\section{Aim}

This study was conducted to study the pattern of PET/ CT scan use in the non-colorectal GI malignancies (cohort 1) at our institute, which is one of the largest tertiary medical centers in the middle east, and its adherence to evidence based guidelines, to identify the rate of suspicious/equivocal versus clear positive or clear negative results and whether the pathological pursuit was carried out for those indeterminate lesions or not, and finally to identify the rate at which PET scan has changed the management plan during the study period.

Colorectal cancers (cohort 2) will be done in a different study. The study design was a retrospective design.

\section{Methods}

All cases of non-colorectal gastrointestinal cancers (NCGIC), diagnosed from January 1, 2007, to December 31,2008 , were identified using the cancer registry database "the hospital tumor registry software CNExT (C/ NET Solutions, Berkeley, CA).” NCGIC include esophageal cancer, gastroesophageal junction and gastric cancer, pancreatic cancer, hepatobiliary cancers, and GI well-differentiated neuroendocrine tumors. Those who had PET/CT scan at our institute were identified. Data collection form (DCF) was filled out for each case using data from the patient's paper and electronic charts. Descriptive statistics were used for patient characteristics and best tumor response. Tabulation and statistical data 
analysis were done using JMP-SAS statistical software application (version 9.4: SAS Institute, Cary, NC, USA).

\section{Ethics approval and consideration}

This study was conducted in accordance with the ethical principles contained in the Declaration of Helsinki (2000), Good Clinical Practice Guidelines, and policies and guidelines of the Research Advisory Council (RAC) in our institute and approved by the Medical Ethics Committee, under project number (ONC-RU/370/ 2111069). The identity of the patients studied remained anonymous since no identifying data or protected health information were recorded. All data were password secured to safeguard the confidentiality of the collected patient's data.

This research has been consented for publication from the office of research affair (ORA), according to the internal regulation of our institutes, and all authors read and approved the final manuscript.

\section{Results}

Two hundred thirty-seven patients were found with non-colorectal gastrointestinal cancers from January 1, 2007, to December 31, 2008 (over 24 months). Of them, 77 patients (32.5\%) had 107 PET/CT scans till July 2015 (last date of data collection). Median age was 59 (21-86) years. Males were 45 (58.8\%).

Their primary diagnosis was as follows (Fig. 1): 46.8\% esophageal cancer and gastroesophageal junction (GEJ) cancer, $15.6 \%$ gastric cancers, $11.7 \%$ pancreatic cancers, $11.7 \%$ hepatobiliary tumors, $10.4 \%$ neuroendocrine tumors, $2.6 \%$ gastrointestinal stromal tumors (GIST), and $1.3 \%$ small bowel cancer.

Indications of requesting PET/CT (Fig. 2) were as follows: staging in $59.8 \%$, follow-up after finishing treatment in $14.9 \%$, restaging at relapse in $8.4 \%$, assessing response after/during treatment in $3.7 \%$, FU of previous $\mathrm{PET} / \mathrm{CT}$ in $12.1 \%$, and others in $0.9 \%$.

PET/CT changed the stage in (19.6\%), either upstaged due to new lesions ( 6 of them were lymph nodes, liver lesion in 4, others either in adrenal gland or bone), while 1 patient was downstaged, and affected treatment plan in $11.2 \%$, either upstaged, where we canceled their radical surgery and changed to palliative chemo treatment, diagnosed progressive disease, and stopped treatment, or downstaged, then the patient was eligible for curative surgery.

PET/CT reported indeterminate or equivocal results in $32(29.9 \%)$ out of 107 scans (Fig. 3). Those data were taken directly from the exact wording of the radiology reports indicating inconclusive results of such scans; lesions were considered indeterminate if false-positive or false-negative settings were highly suspected, if they had no or minimal FDG avidity because of small size, or if the clinical settings indicate false-positive results such as inflammatory or post-operative settings. Examples are in Fig. 4 a, b. In the first case (Fig. 4a), PET showed indeterminate result due to mediastinal mass of low avidity, and pathological pursuit was done by FNA which was negative for malignancy. While in Fig. 4b, PET showed indeterminate lesion in the left adrenal gland, and pathological pursuit was not done due to appearance of peritoneal lesions, which indicate progressive disease. Investigators reviewed the clinical setting of each PET/ CT scan, and as per their best clinical judgment, there was a need for pathological pursuit because findings were indeterminate in 52 scans; of them, PET/CT for the lesions that could have changed the stage reported indeterminate/equivocal results in 32 (29.9\%) of all scans. However, the pathological pursuit for the equivocal lesions on PET/CT scans was done in only 12 of 52 (23.1\%) scans (Fig. 5).

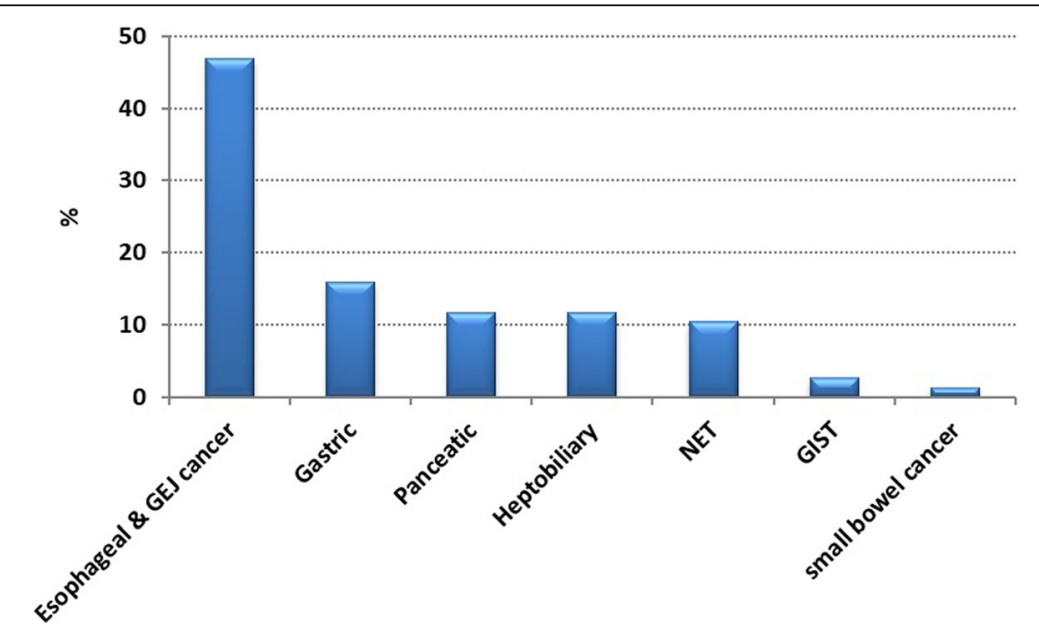

Fig. 1 Primary tumor origin of cases 


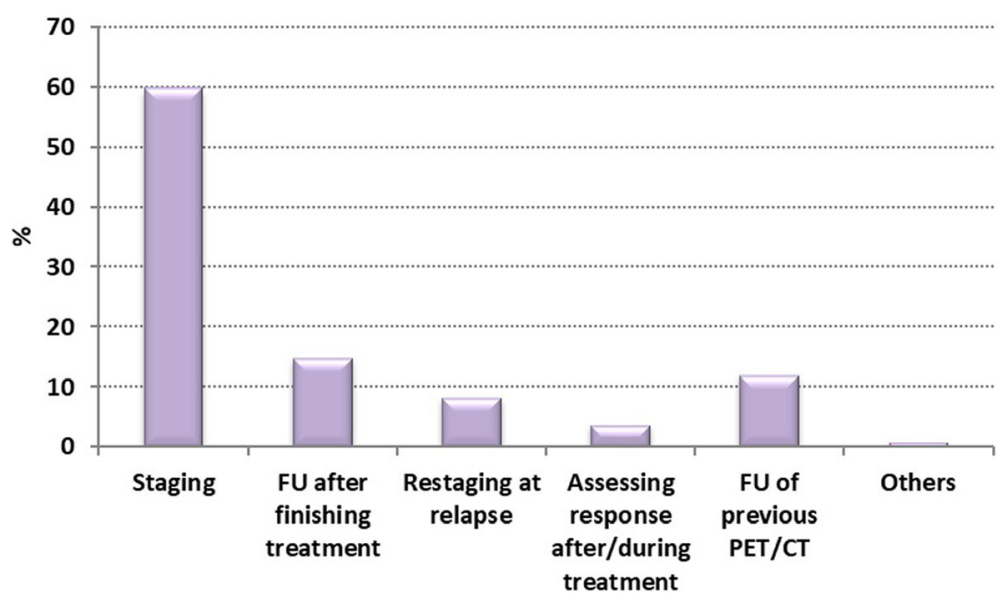

Fig. 2 Indications of PET/CT scan

\section{Discussion}

PET-CT is a powerful radiological tool in different management stages of gastrointestinal malignancies including staging workup and post-treatment follow-up. But as an investigational tool, it has its own limitations. Besides its high cost, false negative and false positive as well as equivocal results are the main limitations. This study done at our institute shows a high rate of non-adherence to the guidelines with almost $60 \%$ of PET/CTs ordered for staging purposes, while results of many studies show its lower yield in staging workup.

A systematic review of 12 studies of the staging use of PET scan in esophageal cancer revealed sensitivity of $51 \%$ and specificity of $84 \%$ in detecting locoregional disease and sensitivity of $67 \%$ and specificity of $97 \%$ in detecting distant metastasis [6]. And for locoregional $\mathrm{N}$ staging, high false-positive results of FDG-PET have been found and most of them related to an inflammatory process [7].

However, the extra benefit of PET over CT scan in the preoperative staging evaluation of esophageal cancer was tested in a randomized trial conducted by the American College of Surgeons Oncology Group, in which 262 patients with non-metastatic potentially cases after CT of the chest and abdomen were randomly assigned to PET or no PET [8]. With the caveat that 22 percent of eligible patients did not undergo esophagectomy for a variety of reasons, PET after standard clinical staging identified biopsy-confirmed M1b disease in only nine patients (5\%) and unconfirmed evidence of M1b disease (which was accepted by the surgeon as evidence of metastases without biopsy confirmation) in 18 others (10\%). An important limitation of the trial was that the integrated PET/CT was not used.

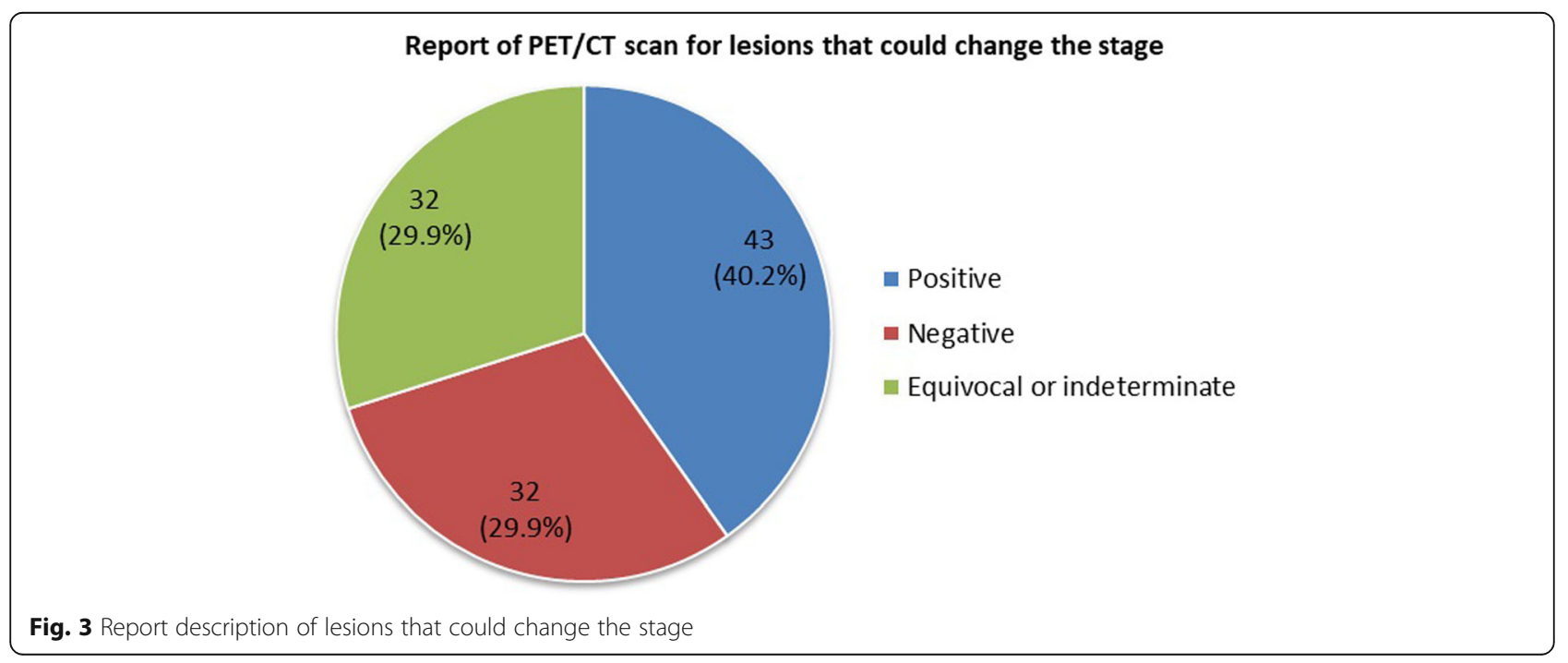


(A)

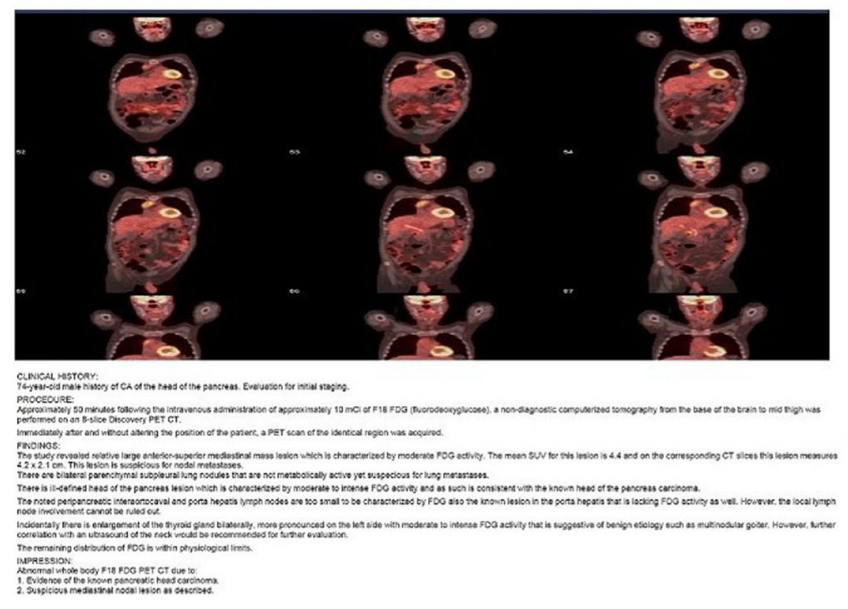

(B)

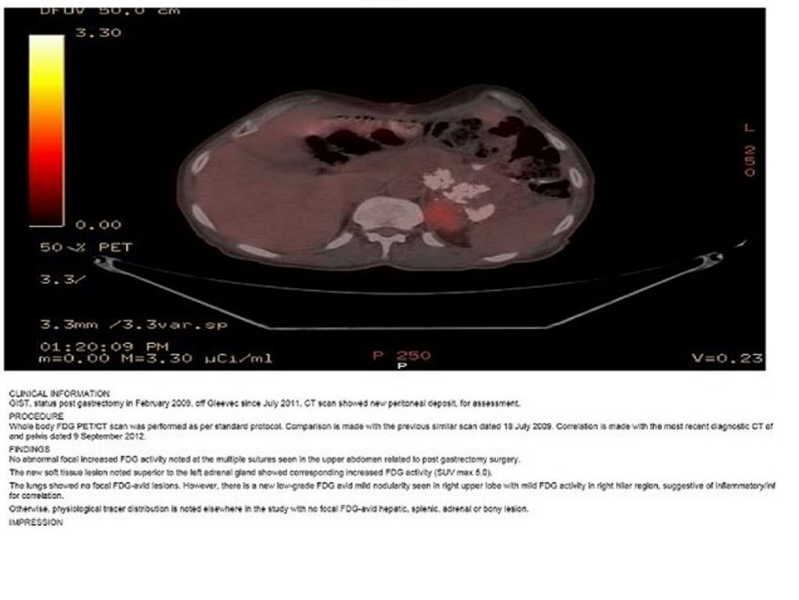

Fig. 4 a PET of pancreatic cancer patient showed equivocal mediastinal mass. b PET-CT of gastric cancer patient showed equivocal left adrenal mass

For primary gastric malignancy, $\mathrm{PET} / \mathrm{CT}$ is associated with a low detection rate (about 55\%), especially for early stage, as well as mucinous, signet-ring cell, and poorly differentiated adenocarcinomas, which are typically less metabolically active [9-17].

Moreover, it is not uncommon to see variable and occasionally intense physiological uptake within the gastric wall, which may mask FDG uptake by the primary tumor. In addition to that, increased FDG uptake may also correspond to the presence of gastritis. Therefore, $\mathrm{PET} / \mathrm{CT}$ has a limited role in the detection and $\mathrm{T}$ staging of gastric cancer.

In patients with pancreatic cancers, Glucose intolerance is frequently encountered. High serum glucose level can compete with FDG uptake in the pancreatic tumor and can even lead to false-negative PET findings [18].
The performances of PET/CT for detecting malignant pancreatic tumors have been shown to be equivalent to magnetic resonance imaging [19-22].

In gastrointestinal stromal tumors, PET/CT is now the imaging modality of choice because of its high sensitivity in assessing early therapeutic response to imatinib or other targeted therapies [23]. Thus, PET/CT is beneficial in doubtful cases and when the early prediction of response is of special concern (e.g., preoperative cytoreductive treatments).

Also, PET/CT is not recommended for the detection of hepatocellular carcinoma (HCC), as several studies have demonstrated variable FDG uptake values due to wide range of levels of glucose-6-phosphatase activity and glucose transporters present in HCC [24-27], with an overall sensitivity of $50-65 \%$ [28-30].

\section{Pathological pursuit of $\mathrm{PET} / \mathrm{CT}$ indeterminate result that could change} the stage

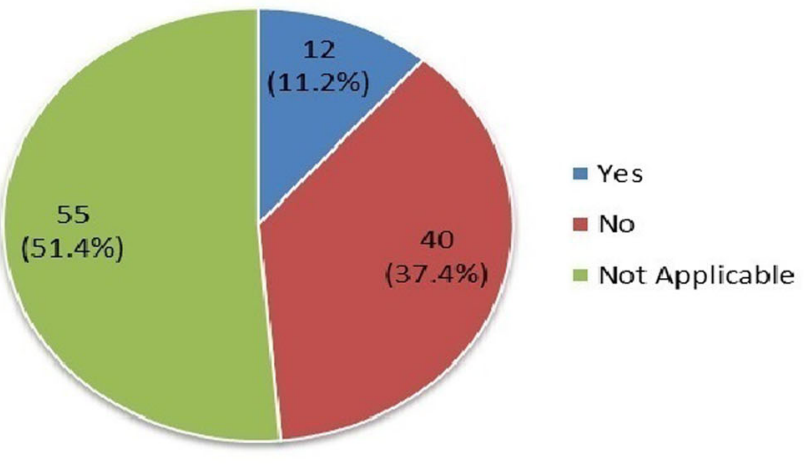

* Of the 52 scans that were decided by investigators that a pathological pursuit was needed, Only 12 cases (23.2\%) had pa thological pursuit

Fig. 5 Pathological pursuit of PET/CT indeterminate result that could change the stage 
According to the FFCD, NCCN, and ESMO guidelines, $\mathrm{PET} / \mathrm{CT}$ is presently not recommended in the diagnosis, staging, and management of HCC.

In gallbladder cancer, there is a lack of evidence supporting the use of PET, and larger studies still needed to determine the potential of this technique in influencing patient outcomes.

In our study, PET/CT changed the stage in $19.6 \%$ of cases and changed the management plan in $11.2 \%$ only, while in many studies, PET findings led to a significant change in patient management in about one third of the patients in esophageal cancer [31, 32], and in gastric cancer, gastrectomy was shown to be unnecessary in 6$10 \%$ of patients [33].

Our explanation for this lower rate of impact on stage and/or management is the lack of accurate interpretation of PET-CT results that could be due to overuse in non-indicated clinical scenarios, which lead to dilution of clinically significant results.

Early detection of recurrence using imaging techniques is challenging due to tissue changes induced by surgery and/ or radiotherapy. However, the available data are insufficient to draw any conclusion and PET/CT cannot be widely recommended in this setting. And our results in this setting was $27 \%$ of all requested PET-CT (14.9\% in follow-up after the end of treatment, $8.4 \%$ in restaging at relapse, assessing response after/during treatment in 3.7\%), which present a huge portion in non-indicated setting.

In this study, PET/CT scan reported indeterminate or equivocal results in 32 out of 107 scans (29.9\%) which is a relatively high equivocal reporting of lesions. Generally, lesions were considered indeterminate if false-positive or false-negative settings were highly suspected, if they had no or minimal FDG avidity because of small size, or if the clinical settings indicate false-positive results such as inflammatory or post-operative settings. Investigators reviewed the clinical setting of each scan, and as per their best clinical judgment on a retrospective basis, they decided that in 52 scans (out of the total 107), there was a need for pathological pursuit because findings were indeterminate and that could have changed the stage and hence affected the management. However, that was only done after 12 scans of those 52 (23.1\%), and that is a low percentage of further confirmation with pathology and could be due to lack of knowledge of PET/CT scan limitations including falsepositive results which leads to over trust of $\mathrm{PET} / \mathrm{CT}$ by some treating physicians.

Therefore, pathology in certain clinical scenarios remains the standard tool to confirm the presence of malignancy and should not be replaced by PET.

The main flaws or limitations of the study were as follows:
The sample selected was from 2007 to 2008 and followed to 2015, which was the time of implementing $\mathrm{PET} / \mathrm{CT}$ at our institute and time to examine adherence to guidelines and test its limitations. Data collection does not undermine the credibility or validity of these data because the diagnostic approach, as well as clinical settings, has not changed.

The sample size is 77 cases, which underwent 107 scans, which was chosen to fulfill the aim of the study to see the pattern of use of PET/CT scan in GI cancers and to check the adherence to the NCCN guidelines. Sensitivity and specificity PET/CT are completely out of the scope of this study. It is basically an assessment of the use of certain diagnostic tool in certain situations at a certain place and not diagnostic research that should have a certain sample size for a threshold of sensitivity and specificity. Therefore, the sample size was not necessarily large, and in order to see representation from all types of the GI cancers, cases of non-colorectal GI cancers were lumped together because what we are interested in is to see the pattern of use and not the clinical yield of PET/CT scan. Having said that, the cases for colorectal cancer were preplanned to be published in a separate report and we planned to just publish the data on non-colorectal cases in this report.

Last, the study did not dwell on the reasons for not pursuing the pathological diagnosis, because they were either dangerous to perform the biopsy or due to the interventional radiologist refusal or even the patient refused after the risks were explained to him.

\section{Conclusion}

This study shows low adherence to the NCCN guidelines of the use of PET/CT scan in the management of GI malignancies, which in turn leads to overuse or even abuse of PET/CT scanning. PET/CT scan is very useful in many case scenarios but should not be done routinely.

Physicians requesting PET/CT scan need to know the causes and rate of the false-positive and false-negative results which make the main caveat in PET/CT interpretation. On the other hand, most of the positive or equivocal lesions in this study were not pursued by pathological confirmation even if they are management changing. Pathology remains the standard method to confirm the presence or absence of cancer at any site and should not be replaced by PET/CT except in special clinical situations.

\section{Supplementary information}

Supplementary information accompanies this paper at https://doi.org/10. 1186/s43055-019-0067-y.

Additional file 1: Database 


\section{Abbreviations}

$\mathrm{CT}$ : Computed tomography; DCF: Data collecting form; ESMO: European Society of Medical Oncology; FDG: Fluorodeoxyglucose; FFCD: Fédération Francophone de Cancérologie Digestive; FNA: Fine-needle aspiration; GEJ: Gastroesophageal junction; GI: Gastrointestinal; GIST: Gastrointestinal stromal tumors; HCC: Hepatocellular carcinoma; MR: Magnetic resonance; MRI: Magnetic resonance imaging; NCCN: National Comprehensive Cancer Network; NCGIC: Non-colorectal gastrointestinal cancers; PET: Positron emission tomography; PET/CT: Positron emission tomography/computed tomography; RAC: Research Advisory Council

\section{Acknowledgements}

Not applicable

\section{Authors' contributions}

AJ contributed to the conception, design of the study, and analysis of the data. $A B$ contributed to the design of the study, analysis of the data, and manuscript writing. OS contributed to the data collection and analysis of the data. $\mathrm{HH}$ contributed to the data collection and analysis of the data. AO contributed to the data collection and analysis of the data. AE contributed to the statistical analysis. All authors have read and approved the manuscript.

\section{Funding}

This research received no specific grant from any funding agency in the public, commercial, or not-for-profit sectors.

\section{Availability of data and materials}

All data generated or analyzed during this study are included in this published article [under excel sheet name: Database].

\section{Ethics approval and consent to participate}

This research project was conducted in accordance with the ethical principles contained in the declaration of Helsinki (2000), Good Clinical Practice Guidelines, and the policies and guidelines of the Research Advisory Council (RAC) in KFSH\&RC and approved by the Medical Ethics Committee under project number (ONC-RU/370/2111069). The identity of the patients studied remained anonymous since no identifying data or protected health information were recorded. All data were password secured to safeguard the confidentiality of the collected patient's data. This research has been consented for publication from office of research affair (ORA), according to internal regulation of $\mathrm{KFSH} \& \mathrm{RC}$, and all authors read and approved the final manuscript.

\section{Consent for publication}

Patients' consent to treatment is also approved for the use of their medical records in the research, The Research Advisory Council (RAC) has the right of access to the supporting records for all research at the KFSH\&RC.

This research has granted approval by RAC in KFSH\&RC, under project number (ONC-RU/370/2111069), and was approved by the Institutional Review Board (IRB), which evaluates the ethical aspects of all research proposals that involve human subjects.

The RAC waiver consent includes access and use of patient files while maintaining the confidentiality of their data. The identity of the patients studied remained anonymous since no identifying data or protected health information were recorded. All data were password secured to safeguard the confidentiality of the collected patient's data.

\section{Competing interests}

The authors declare that they have no competing interests.

\section{Author details}

${ }^{1}$ Medical Oncology, Oncology Centre, King Faisal Specialist Hospital and Research Center, MBC 64, PO Box 3354, Riyadh 11211, Saudi Arabia. 2Department of Clinical Oncology, Faculty of Medicine, Ain Shams University, Cairo, Egypt. ${ }^{3}$ Section of oncology, Security Forces Hospital, Riyadh, Saudi Arabia. ${ }^{4}$ Department of Clinical Oncology, Faculty of Medicine, Suez Cannel University, Ismailia, Egypt. ${ }^{5}$ Department of Biostatistics, Epidemiology and Scientific Computing, Research Center, King Faisal Specialist Hospital and Research Center, Riyadh, Saudi Arabia.
Received: 12 June 2019 Accepted: 16 October 2019

Published online: 27 November 2019

\section{References}

1. Bentley-Hibbert S, Schwartz L (2015) Use of imaging for Gl cancers. J Clin Oncol 2015; 33:1729-1737. https://doi.org/10.1200/JCO.2014.60.2847

2. Agarwa A, Marcus C, Xiao J et al (2014) FDG PET/CT in the management of colorectal and anal cancers. Am J Roentgenol 203:1109-1119 https://doi. org/10.2214/AJR.13.12256

3. Phelps ME, Hoffman EJ, Mullani NA, Ter-Pogossian MM (1975) Coincidence detection to transaxial reconstruction tomography. J Nucl Med $1975 ; 16$ : 210-224; PMID:1113170

4. Gallagher BM, Fowler JS, Gutterson NI, et al (1978) Metabolic trapping as a principle of radiopharmaceutical design: some factors responsible for the biodistribution of [18F] 2-deoxy-2-fluoro-D-glucose. J Nucl Med 1978; 19: 1154-1161; PMID:214528

5. Podoloff DA, Advani RH, Allred C, et al (2007) JNCCN NCCN Task Force Report: PET/CT scanning in cancer, Volume 5 Supplement 1. J Natl Compr Canc Netw. 2007 May;5 Suppl 1:S1-22; quiz S23-2. PMID:17509259

6. Van Westreenen HL, Westerterp M, Bossuyt PMM et al (2004) Systematic review of the staging performance of 18F-fluorodeoxyglucose positron emission tomography in esophageal cancer. J Clin Oncol 22:3805-3812 https://doi.org/10.1200/JCO.2004.01.083

7. Yoon YC, Lee KS, Shim YM et al (2003) Metastasis to regional lymph nodes in patients with esophageal squamous cell carcinoma: $C T$ versus FDG PET for presurgical detection- prospective study. Radiology 227:764-770 https://doi.org/10.1148/radiol.2281020423

8. Meyers BF, Downey RJ, Decker PA et al (2007) The utility of positron emission tomography in staging of potentially operable carcinoma of the thoracic esophagus: results of the American College of Surgeons Oncology Group Z0060 trial. J Thorac Cardiovasc Surg 133 https://doi.org/10.1016/j. jtcvs.2006.09.079

9. Alakus H, Batur M, Schmidt M, et al (2010) Variable 18F-fluorodeoxyglucose uptake in gastric cancer is associated with different levels of GLUT-1 expression. Nucl Med Commun 31: 2010 Jun;31(6):532-538. https://doi.org/ 10.1097/MNM.0b013e32833823ac.

10. Stahl A, Ott K, Weber W et al (2003) FDG PET imaging of locally advanced gastric carcinomas: correlation with endoscopic and histopathological findings. Eur J Nucl Med Mol Imaging 30:288-295 https://doi.org/10.1007/ s00259-002-1029-5

11. Yoshioka T, Yamaguchi K, Kubota K, et al (2003) Evaluation of 18 F-FDG PET in patients with advanced, metastatic, or recurrent gastric cancer. J Nucl Med 2003; 44: 690-699; PMID:12732669

12. Kim S-K, Kang KW, Lee JS et al (2006) Assessment of lymph node metastases using 18F-FDG PET in patients with advanced gastric cancer Eur J Nucl Med Mol Imaging 33:148-155 https://doi.org/10.1007/s00259005-1887-8

13. Yun M, Lim JS, Noh SH, Hyung WJ, Cheong JH, Bong JK, et al (2005) Lymph node staging of gastric cancer using 18 F-FDG PET: a comparison study with CT. J Nucl Med. 2005; 46: 1582-1588. PMID:16204706

14. Oh HH, Lee SE, Choi IS et al (2011) The peak-standardized uptake value (PSUV) by preoperative positron emission tomography-computed tomography (PET-CT) is a useful indicator of lymph node metastasis in gastric cancer. J Surg Oncol 104:530-533 https://doi.org/10.1002/jso.21985

15. Hur H, Kim SH, Kim W et al (2010) The efficacy of preoperative PET/CT for prediction of curability in surgery for locally advanced gastric carcinoma. World J Surg Oncol https://doi.org/10.1186/1477-7819-8-86

16. Yamada A, Oguchi K, Fukushima M et al (2006) Evaluation of 2-deoxy-2[18F]fluoro-D-glucose positron emission tomography in gastric carcinoma: relation to histological subtypes, depth of tumor invasion, and glucose transporter-1 expression. Ann Nucl Med 20:597-604 https://doi.org/10.1007/ bf02984657

17. Mukai K, Ishida Y, Okajima K et al (2006) Usefulness of preoperative FDG-PET for detection of gastric cancer. Gastric Cancer https://doi.org/10.1007/ s10120-006-0374-7

18. Zimny M, Bares R, Fass J, Adam G, Cremerius U, Dohmen B, Klever P, Sabri O, Schumpelick V, Buell U (1997) Fluorine-18 fluorodeoxyglucose positron emission tomography in the differential diagnosis of pancreatic carcinoma: a report of 106 cases. Eur J Nucl Med 24:678-682 https://doi.org/10.1007/ bf00841409 
19. Tann M, Sandrasegaran K, Jennings SG et al (2007) Positron-emission tomography and computed tomography of cystic pancreatic masses. Clin Radiol 62:745-751 https://doi.org/10.1016/j.crad.2007.01.023

20. Sperti C, Pasquali C, Chierichetti F et al (2001) Value of 18fluorodeoxyglucose positron emission tomography in the management of patients with cystic tumors of the pancreas. Ann Surg https://doi.org/10 1097/00000658-200111000-00014

21. Sperti C, Bissoli S, Pasquali C et al (2007) 18-Fluorodeoxyglucose positron emission tomography enhances computed tomography diagnosis of malignant intraductal papillary mucinous neoplasms of the pancreas. Ann Surg 246:932-937 https://doi.org/10.1097/SLA.0b013e31815c2a29

22. Kauhanen SP, Komar G, Seppanen MP (2009) A prospective diagnostic accuracy study of (18)F-fluorodeoxyglucose positron emission tomography/ computed tomography, multidetector-row computed tomography and magnetic resonance imaging in primary diagnosis and staging of pancreatic cancer. Ann Surg 250:957 https://doi.org/10.1097/sla. 0b013e3181b2fafa

23. Basu S, Mohandas KM, Peshwe $\mathrm{H}$ et al (2008) FDG-PET and PET/CT in the clinical management of gastrointestinal stromal tumor. Nucl Med Commun 29:1026-1039 https://doi.org/10.1097/MNM.0b013e328313bbe7

24. Torizuka T, Tamaki N, Inokuma T, et al (1995) In vivo assessment of glucose metabolism in hepatocellular carcinoma with FDG- PET. J Nucl Med. 36(10): 1811-1817. PMID: 7562048

25. Salem N, MacLennan GT, Kuang Y et al (2007) Quantitative evaluation of 2Deoxy-2[F-18]fluoro-d-glucose-positron emission tomography imaging on the woodchuck model of hepatocellular carcinoma with histological correlation. Mol Imaging Biol 9:135-143 https://doi.org/10.1007/s11307-007-0092-5

26. Lee JD, Woo Yang I, et al (2005) Different glucose uptake and glycolytic mechanisms between hepatocellular carcinoma and intrahepatic massforming cholangiocarcinoma with increased 18 F-FDG uptake. J Nucl Med.; 46:1753-1759. PMID: 16204727

27. Roh MS, Jeong JS, Kim YH, Kim MC, Hong SH (2004) Diagnostic utility of GLUT1 in the differential diagnosis of liver carcinomas. Hepatogastroenterology 51:1315-1318. PMID: 15362741

28. Khan MA, Combs CS, Brunt EM et al (2000) Positron emission tomography scanning in the evaluation of hepatocellular carcinoma. J Hepatol 32:792$797 \mathrm{https}: / /$ doi.org/10.1016/S0168-8278(00)80248-2

29. Ho C-L, Yu SCH, Yeung DWC (2003)11 C-Acetate PET imaging in hepatocellular carcinoma and other liver masses. J Nucl Med.; 44:213-221. PMID:12571212

30. Rose AT, Rose DM, Pinson CW, Wright JK, Blair T, Blanke C, Delbeke D, Debelak JP, Chapman WC (1998) Hepatocellular carcinoma outcomes based on indicated treatment strategy. Am Surg 64:1128-1134. PMID:9843330

31. Barber TW, Duong CP, Leong T et al (2012) 18F-FDG PET/CT has a high impact on patient management and provides powerful prognostic stratification in the primary staging of esophageal cancer: a prospective study with mature survival data. J Nucl Med https://doi.org/10.2967/jnumed. 111.101568

32. Chen J, Cheong JH, Mi JY et al (2005) Improvement in preoperative staging of gastric adenocarcinoma with positron emission tomography. Cancer https://doi.org/10.1002/cncr.21074

33. Smyth E, Schöder H, Strong VE et al (2012) A prospective evaluation of the utility of 2-deoxy-2-[18F] fluoro- D -glucose positron emission tomography and computed tomography in staging locally advanced gastric cancer. Cancer 118:5481-5488 https://doi.org/10.1002/cncr.27550

\section{Publisher's Note}

Springer Nature remains neutral with regard to jurisdictional claims in published maps and institutional affiliations.

\section{Submit your manuscript to a SpringerOpen ${ }^{\circ}$ journal and benefit from:}

- Convenient online submission

- Rigorous peer review

- Open access: articles freely available online

High visibility within the field

- Retaining the copyright to your article

Submit your next manuscript at $\boldsymbol{\nabla}$ springeropen.com 